\title{
Características agronômicas e eficiência do uso da chuva em cultivares de sorgo no semiárido
}

\author{
Agronomic characteristics and rain use efficiency of sorghum genotypes in semiarid
}

\author{
Alexandre Fernandes Perazzo ${ }^{\mathrm{I}}$ Edson Mauro Santos ${ }^{\mathrm{II}}$ Ricardo Martins Araújo Pinho ${ }^{\mathrm{II}}$ \\ Fleming Sena Campos ${ }^{\mathrm{I}}$ João Paulo de Farias Ramos ${ }^{I I}$ Marina Montenegro de Aquino ${ }^{\mathrm{II}}$ \\ Thiago Carvalho da Silva ${ }^{\text {III }}$ Higor Fábio Carvalho Bezerra ${ }^{\text {II }}$
}

\section{RESUMO}

Objetivou-se quantificar o rendimento forrageiro, o percentual de componentes da planta, as características morfométricas e a eficiência do uso da chuva de cinco genótipos de sorgo para silagem no semiárido paraibano. O experimento foi conduzido na Estação Experimental Pendência, no município de Soledade-PB. O delineamento experimental utilizado foi em blocos casualizados, com quatro repetições, sendo os tratamentos experimentais representados por cinco genótipos de sorgo: Ponta Negra, SF 15 IPA 1011, IPA 2502 e IPA 46742. Não foram observadas diferenças entre os genótipos para a produção de matéria natural e produção de matéria seca e para o percentual de lâmina foliar. Entretanto, para o percentual de colmo foram observados maiores valores $(P<0,05)$ para os genótipos Ponta Negra e IPA 46742. O percentual de panícula foi superior $(P<0,05)$ para as cultivares 'IPA 1011'e 'IPA 2502'. As cultivares 'IPA 1011'e 'IPA 2502' apresentaram percentual de panícula acima de $38 \%$ da MS. Não houve diferença $(P<0,05)$ para eficiência no uso da água de chuva entre os genótipos estudados, com valores variando de 94,37 a 126,25kg de MS ha-1 $\mathrm{mm}^{-1}$. Os genótipos avaliados apresentam elevada eficiência no uso da chuva e produtividade. Recomenda-se o IPA 1011 pela maior participação de panícula.

Palavras-chave: altura da planta, forragem, matéria seca, precipitação.

\section{ABSTRACT}

The objective was to quantify the forage yield, percentage of plant components, the morphometric characteristics and the rain use efficiency of five genotypes of sorghum silage in semiarid of Paraiba. The experiment was conducted at the Experimental Station Pendência, municipality ofSoledade-PB. The experimental design used was randomizedblocks with four replicates, being experimental treatments represented by five sorghum genotypes: Ponta Negra, SF 15 IPA 1011, IPA 2502 and
IPA 46742. No differences had been observed between genotypes for the production of natural matter and dry matter production. For the percentage of leafblade was not significant difference $(P>0.05)$, however for the percentage of stem showed higher $(P<0.05)$ for genotypes Ponta Negra and IPA 46742. The percentage of panicle was high $(P<0.05)$ for cultivars 'IPA 1011' and 'IPA 2502'. The cultivars 'IPA 1011'e 'IPA 2502' showed panicle percentage above $38 \%$ DM. There was no difference $(P<0.05)$ in rain-use efficiency among genotypes, with values ranging from 94.37 to $126.25 \mathrm{~kg} D M$ $\mathrm{ha}^{-1} \mathrm{~mm}^{-1}$. The genotypes showed high use efficiency of rain can and productivity, which is recommended by the IPA 1011 increased participation panicle.

Key words: dry matter, forage, plant height, precipitation.

\section{INTRODUÇÃO}

A região semiárida do nordeste brasileiro é caracterizada pela ocorrência de precipitações que se distribuem de maneira irregular, concentradas num curto período chuvoso, seguido de um longo período sem chuvas. Essa característica climática é o principal fator que afeta a produção agropecuária dessa região, sendo importante a aplicação de estratégias específicas para obter maior rendimento na produção de forragens.

A escassez de forragem, agravada no período seco, e o baixo valor nutritivo das forrageiras de ocorrência natural comprometem o crescimento e o desenvolvimento dos animais, acarretando queda de produtividade e comprometendo a produção de leite e

\footnotetext{
'Universidade Federal da Bahia (UFBA), 10170-110, Salvador, BA, Brasil. E-mail: alexandreperazzo@hotmail.com.*Autor para correspondência.

"Universidade Federal da Paraíba (UFPB), Areia, PB, Brasil.

IIIUniversidade Federal de Viçosa (UFV), Viçosa, MG, Brasil. 
carne, passando, assim, os produtores a depender da disponibilidade de volumosos conservados (LIMA et al., 2004).

Nesse contexto, a cultura do sorgo se destaca por ter uma produção de matéria seca (MS) superior à do milho, apresentando principalmente a vantagem de uma maior adaptabilidade a regiões com distribuição irregulares de chuvas, com solos rasos e de baixa fertilidade, que são características de regiões semiáridas (ROCHA JÚNIOR et al., 2000).

Assim, o cultivo de plantas como o sorgo pode viabilizar a produção animal no semiárido paraibano, aliado a outras plantas forrageiras adaptadas e produtivas nessas condições, como o capim buffel (EDVAN et al., 2011), a palma forrageira (RAMOS et al., 2011), dentre outras.

Ultimamente, tem-se desenvolvido e lançado vários genótipos de sorgo no mercado. No entanto, pesquisas são essenciais para a caracterização agronômica e nutricional desses genótipos, proporcionando uma recomendação mais precisa dos genótipos promissores para as mais diversas utilidades nos sistemas de produção, principalmente, na região semiárida.

TABOSA et al. (2002), avaliando 20 cultivares de sorgo forrageiro nos Estados de Pernambuco e Alagoas, concluíram que a associação das variáveis de produção e a eficiência do uso de água são parâmetros adequados para seleção de material de sorgo forrageiro no semiárido.Diante do exposto, objetivou-se quantificar o rendimento forrageiro, o percentual de componentes da planta e a eficiência no uso da água de chuva, bem como avaliar as características agronômicas de cinco cultivares de sorgo para produção de silagem no semiárido paraibano.

\section{MATERIAL E MÉTODOS}

O experimento foi conduzido na Estação Experimental de Pendência, da empresa Estadual de Pesquisa Agropecuária da Paraíba S.A - (EMEPA), situada na Mesorregião do Agreste paraibano, Microrregião do Curimataú, Município de Soledade, Paraíba. Baseado na classificação de Köppen, o tipo climático da região é Bsh com umidade relativa do ar em torno de $68 \%$, ocorrendo precipitação média de 400mm anuais, apresenta temperaturas médias anuais em torno de $30^{\circ} \mathrm{C}$, com déficit hídrico durante quase todo ano.

A análise do solo da área experimental foi realizada no laboratório da Universidade Federal da Paraíba, apresentando os seguintes atributos químicos no perfil de 0 a 20cm: $\mathrm{pH}\left(\mathrm{H}_{2} \mathrm{O}\right)$ 6,94; $\mathrm{P}$ 70,38 e $\mathrm{K}^{+} 82,0 \mathrm{mg} \mathrm{dm}{ }^{-3} ; \mathrm{Na}^{+} 0,37 ; \mathrm{H}^{+}+\mathrm{Al}^{+3}$ 2,06; $\mathrm{Al}^{+3}$ 0,$0 ; \mathrm{Ca}^{+2} 7,45 \mathrm{e} \mathrm{Mg}^{+2} 2,40 \mathrm{cmol}_{\mathrm{c}} \mathrm{dm}^{-3}$; saturação por bases $83,51 \%$ e, matéria orgânica $10,55 \mathrm{~g} \mathrm{~kg}^{-1}$.

Utilizou-se um delineamento experimental em blocos casualizados, com quatro repetições. Os tratamentos experimentais foram representados por cinco genótipos de sorgo (Sorghum bicolor (L). Moench). Os genótipos avaliados foram: Ponta Negra, SF 15, IPA 46742 , IPA 2502 e IPA 1011.

Foi realizada uma adubação nitrogenada com $100 \mathrm{~kg} \mathrm{ha}^{-1}$ de $\mathrm{N}$, na forma de sulfato de amônio, aplicada manualmente e dividida em duas aplicações, sendo a primeira 15 dias após emergência (DAE), com50kg de $\mathrm{N}^{-1}$, e a segunda aos 45DAE, com $50 \mathrm{~kg}$ de $\mathrm{N} \mathrm{ha}^{-1}$. Com base na análise de solo, não foi necessária a aplicação de fósforo e potássio.

A semeadura da gramínea foi realizada em maio de 2010 em parcelas de 4,0 $\mathrm{m}^{2}$ (2,0x2,0m), com espaçamento de $0,7 \mathrm{~m}$ entre linhas. Aos 15 dias após a semeadura (DAS), foi realizado um desbaste, conservando 12 plantas por metro linear. Aos 30DAS, foi conduzida uma capina com o auxílio de enxadas. A duração do período experimental foi de 98 dias com um acumulado de chuva de $115 \mathrm{~mm}$ registradas na Estação Meteorológica da Estação Experimental Pendência, da Empresa de Pesquisa Agropecuária da Paraíba S.A (EMEPA). De acordo com a figura 1, observam-se os dados diários de precipitação pluvial dos meses de maio a agosto de 2010, ocorridas no período experimental. O sorgo foi colhido quando os grãos apresentavam-se no estágio pastoso. O corte de avaliação foi efetuado manualmente com cutelos, a $10 \mathrm{~cm}$ acima do solo, obtendo como área útil as duas linhas centrais de cada parcela. Foi retirada uma subamostra de cada tratamento, para posterior présecagem em estufa com ventilação forçada a $65^{\circ} \mathrm{C}$, até atingir peso constante, a fim de estimar seu teor de matéria seca (MS).

Para fins da avaliação, foi considerada a produção de dois metros de sulco por parcela. A produção de matéria verde (PMV), dada em $\mathrm{kg} \mathrm{ha}^{-1}$, foi obtida pelo produto entre a massa verde obtida por metro linear, colhida convertida para o total de metros lineares por hectare. A produção de matéria seca (PMS), em $\mathrm{kg} \mathrm{ha}^{-1}$, foi estimada pelo produto entre a PMV e o teor de MS.

Na colheita, duas plantas representativas por unidade experimental foram coletadas para determinação dos componentes morfológicos: colmo, lâmina foliar, panícula e material morto, que foram pesados para estabelecer a proporção entre os componentes da planta. As amostras dos componentes 


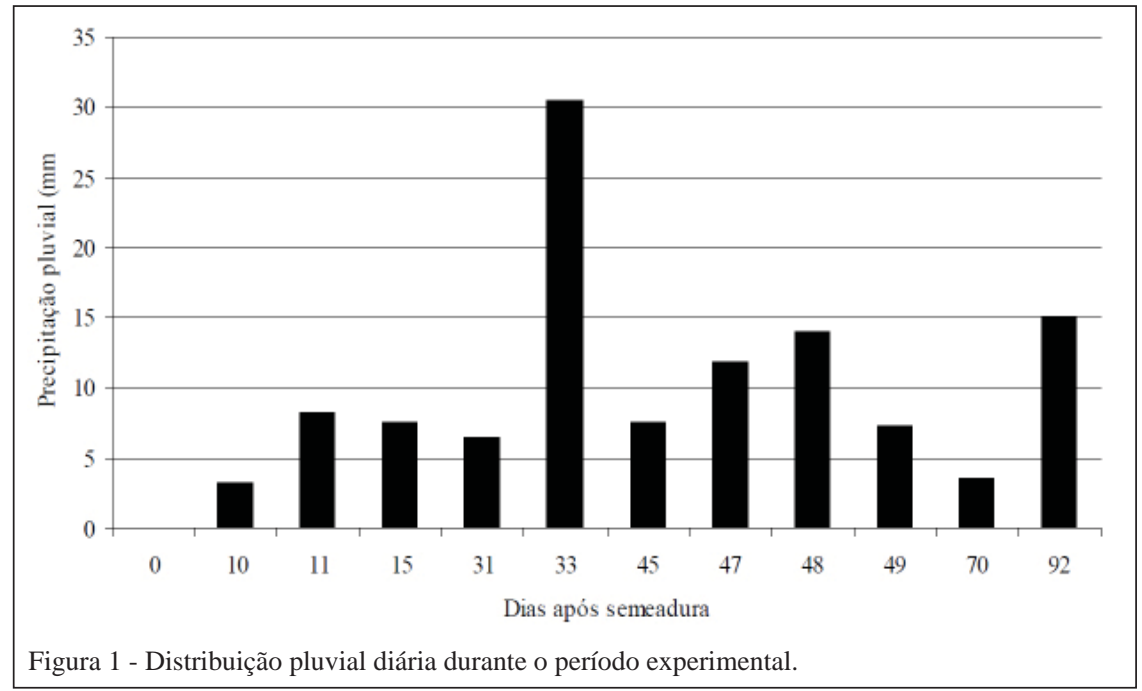

morfológicos foram pesadas e pré-secas em estufa de ventilação forçada a $65^{\circ} \mathrm{C}$, até atingirem peso constante para se estabelecer a proporção com base na MS.

Para a caracterização morfométrica, as mesmas duas plantas de cada parcela foram utilizadas para mensurar a altura das plantas, diâmetro da base do colmo e comprimento médio de folhas (verdes e senescentes), número de nós e o número de folhas verdes. Na análise de variância, foi considerada a média das duas plantas de cada parcela.

A eficiência de uso da chuva (EUC) para a PMS, dada em $\mathrm{kg} \mathrm{ha}^{-1} \mathrm{~mm}^{-1}$, foi estimada pela divisão da PMS pela quantidade de chuva acumulada durante o ciclo (115mm). O acúmulo de água pelas plantas (ACA), em $\mathrm{kg} \mathrm{ha}^{-1} \mathrm{~mm}^{-1}$ foi estimado pela diferença entre a PMV e PMS, posteriormente, dividida pelo total de chuvas em mm.

Os dados foram submetidos à análise de variância e os valores médios foram comparados pelo teste de Tukey, em nível de 5\% de probabilidade, usando-se o programa SISVAR (FERREIRA, 2008).

\section{RESULTADOS E DISCUSSÃO}

Entre as cultivares avaliadas, não houve variação $(\mathrm{P}>0,05)$ para a $\mathrm{PMV}$, apesar dos valores terem variado entre $37.176,71 \mathrm{~kg} \mathrm{ha}^{-1}$ e $52.140,25 \mathrm{~kg}$ ha $^{-1}$ (Tabela 1). Esses resultados são superiores aos encontrados por NEUMANN et al. (2002) em avaliação de híbridos de sorgo, que encontraram variações de 22.707 a 39.563kg ha ${ }^{-1}$. Entretanto, RODRIGUES FILHO et al. (2006), avaliando o potencial produtivo de híbridos, observaram resultados superiores aos encontrados neste estudo, com PMV variando de 45.870 a $67.560 \mathrm{~kg} \mathrm{ha}^{-1}$, o que se deve provavelmente às condições edafoclimáticas do local de estudo.

Os resultados de PMS apresentaram variações menores do que as observadas para a PMV, possivelmente, devido à ausência da influência do percentual de MS. Os valores médios oscilaram $(\mathrm{P}>0,05)$ de $10.882,68 \mathrm{~kg}$ ha $^{-1}$ a $12.073,55 \mathrm{~kg} \mathrm{ha}^{-1}$, com um acumulado de chuvas de $115 \mathrm{~mm}$, o que demonstra o potencial xerofílico e produtivo dos genótipos em estudo.

Tabela 1 - Valores médios de produção de matéria verde (PMV), produção de matéria seca (PMS) e teor de matéria seca (MS) de cultivares de sorgo.

\begin{tabular}{lccc}
\hline Cultivar & PMV $\left(\mathrm{kg} \mathrm{ha}^{-1}\right)$ & PMS $\left(\mathrm{kg} \mathrm{ha}^{-1}\right)$ & MS (\%) \\
\hline 'Ponta negra' & $52.140,25$ & $12.073,55$ & $23,25 \mathrm{e}$ \\
'SF 15' & $42.658,58$ & $10.882,68$ & $25,30 \mathrm{~d}$ \\
'IPA 1011' & $43.547,82$ & $14.519,18$ & $33,34 \mathrm{a}$ \\
'IPA 2502' & $37.176,71$ & $11.807,27$ & $31,70 \mathrm{~b}$ \\
'IPA 46742' & $41.380,07$ & $11.197,48$ & $27,04 \mathrm{c}$ \\
CV (\%) & 21,05 & 21,79 & 2,51 \\
\hline
\end{tabular}

Médias seguidas de letras diferentes na coluna diferem entre si pelo teste de Tukey $(\mathrm{P}<0,05)$.

Ciência Rural, v.43, n.10, out, 2013. 
SILVA et al. (2011), avaliando a produção de matéria seca de 25 híbridos de sorgo no Agreste Paraibano, observaram PMS variando entre 7.679,87 e $20.948,70 \mathrm{~kg} \mathrm{ha}^{-1}$, alguns valores substancialmente acima dos observados no presente trabalho, com um acumulado de chuvas pouco acima de $400 \mathrm{~mm}$. Esses resultados mostram que as cultivares avaliadas no presente estudo apresentaram média de eficiência do uso da chuva (EUC) superior ao observado por SILVA et al. (2011), ou seja, 105,1 contra 44,64kg ha-1 $\mathrm{mm}^{-1}$, demonstrando que, mesmo com PMS inferior, houve um maior aproveitamento no uso da água da chuva para produzir biomassa para o presente estudo, devido às diferenças de precipitações.

Para o percentual de MS, observou-se variação de 23,25\% a 33,34\%, havendo diferenças $(\mathrm{P}<0,05)$ entre os genótipos avaliados, sendo a cultivar 'IPA 1011' com maior teor de MS. Segundo Mc DONALD (1991), o teor de MS da planta é importante no processo de ensilagem, uma vez que este é um dos fatores determinantes do tipo de fermentação que irá se desenvolver dentro do silo. Para produção de silagem de qualidade, o mesmo autor indica que o percentual de MS deve estar acima de 25\%, associados a um adequado nível de carboidratos solúveis. A variedade Ponta Negra apresentou baixo percentual de MS (23\%), em decorrência de seu comportamento forrageiro, enquanto as demais cultivares apresentaram teor de MS esperado para recomendação para produção de silagem. O teor de MS eleva-se mais rapidamente em híbridos de portes médio ou baixo, em função da maior participação de panículas na MS total, devido à baixa umidade desse componente, segundo ZAGO (1991), sendo que é a panícula que determina a finalidade do sorgo: forrageiro, duplo propósito ou granífero. Dessa forma, as diferenças observadas no teor de MS dos genótipos avaliados explicam-se, em parte, pelo percentual de panícula na MS, sendo a cultivar 'IPA 1011' (granífero) com maior $(\mathrm{P}<0,05)$ valor médio (Tabela 2).
Com relação ao percentual de lâmina foliar, não houve diferença $(\mathrm{P}>0,05)$ entre as médias (Tabela 2). Porém, para o percentual de colmo, maiores valores foram observados para as cultivares 'Ponta Negra' e Cultivar 'IPA 46742', com médias de 61,21 e 65,49\%, respectivamente, podendo ser explicado devido ao comportamento forrageiro das cultivares, devido ao porte da planta ser correlacionado positivamente com a participação de colmo.

Para a produção de silagem, torna-se importante a participação do componente colmo nas plantas, pois é onde está localizada a maior parte dos carboidratos solúveis, que são os principais substratos para a fermentação lática, responsável pela adequada preservação da massa ensilada (ZANINE et al., 2007).

Os maiores valores médios $(\mathrm{P}>0,10)$ para o percentual de panícula foram observados para as cultivares 'IPA 1011' e 'IPA 2502', já que os resultados foram, respectivamente, 52,81 e 38,08\%. De acordo com SILVA et al. (2011), a maior participação de panícula na planta de sorgo pode resultar em maior valor nutritivo das silagens, devido à maior quantidade de nutrientes digestíveis totais. O percentual de material morto foi superior para a cultivar 'SF 15', que atingiu 10,77\% desse componente, provavelmente, devido ao maior aceleramento do ciclo desse genótipo, em resposta ao déficit hídrico.

NEUMANN et al. (2002), através da comparação entre os componentes da planta, concluíram que a panícula é o componente da planta de sorgo que determina a qualidade da silagem, por apresentar os maiores teores de MS, proteína bruta (PB) e digestibilidade in vitro da matéria seca (DIVMS) e menores teores de componentes fibrosos em relação ao conjunto colmo e folhas. Entretanto, ressalta-se que, para que o aproveitamento do grão de sorgo seja efetivo, é necessário que este seja desintegrado ou pelo menos quebrado no processo de trituração da forragem.

Tabela 2 - Valores médios dos percentuais com base na matéria seca de lâmina foliar, colmo, panícula e material morto de cultivares de sorgo, com base na matéria seca.

\begin{tabular}{|c|c|c|c|c|}
\hline Cultivar & \% Lâmina foliar & \% Colmo & \% Panícula & \% Material morto \\
\hline 'Ponta negra' & 14,95 & $61,21 a$ & $19,43 c$ & $4,40 b$ \\
\hline 'SF 15' & 17,51 & $50,36 b$ & $21,35 c$ & $10,77 \mathrm{a}$ \\
\hline 'IPA 1011' & 8,62 & $33,71 b$ & $52,81 \mathrm{a}$ & $4,82 b$ \\
\hline 'IPA 2502’ & 13,44 & $43,47 b$ & $38,08 b$ & $4,98 b$ \\
\hline 'IPA 46742' & 10,86 & $65,49 a$ & $17,95 \mathrm{c}$ & $5,68 b$ \\
\hline CV (\%) & 41,39 & 22,36 & 33,21 & 37,94 \\
\hline
\end{tabular}

Médias seguidas de letras diferentes na coluna diferem entre si pelo teste de Tukey $(\mathrm{P}<0,05)$.

Ciência Rural, v.43, n.10, out, 2013. 
Com relação à altura de planta (AP), a cultivar 'Ponta Negra' apresentou uma altura de $2,74 \mathrm{~m}$, sendo superiores às demais $(\mathrm{P}<0,05)$, conforme a tabela 3. Para o DC, os valores médios não apresentaram diferença $(\mathrm{P}>0,05)$ entre os genótipos, variando de 13,87 a $17,75 \mathrm{~mm}$, houve destaque para as cultivares 'Ponta Negra' e 'IPA 46742', o que pode ter influenciado na maior participação do colmo nos dados de componentes da planta, tabela 2. A variável número de nós (NN) apresentou valores diretamente proporcionais aos de AP, ou seja, maior valor AP resultou em maiores $\mathrm{NN}$, como observado para a cultivar 'Ponta Negra'.

Os valores observados para número de folhas vivas (NFV) das cultivares 'SF 15' e 'Ponta Negra’ foram superiores ( $\mathrm{P}<0,05)$, com 6,51 e 6,50, respectivamente. Porém, para tamanho médio de folha (TMF), a cultivar 'Ponta Negra' apresentou maior $(\mathrm{P}<0,05)$ valor em relação às demais cultivares.

A altura ou porte da planta é determinante no comportamento do sorgo, podendo prever características agronômicas. Quando de porte alto, geralmente apresenta maior produção de biomassa, devido ao maior percentual colmo e lâmina foliar, caracterizando um comportamento forrageiro. Para plantas de menor altura, há um maior percentual de panículas, maior teor de MS e provavelmente maior valor nutritivo, demonstrando comportamento de sorgo de duplo propósito.

Diante das diversas características apresentadas pelos genótipos de sorgo, deve-se atentar para rendimentos forrageiros e características agronômicas da planta, conforme a finalidade do uso. Tais aspectos influenciam a indicação de variedades para utilização em pastejo direto, corte verde, silagem e feno.

Com relação à avaliação da eficiência do uso da água de chuva (EUC) para PMS, observouse que, para todas as variáveis analisadas, não houve diferença $(\mathrm{P}>0,05)$, conforme a tabela 4 . Isso demonstra que os diferentes genótipos possuem características semelhantes na EUC, bem como no acúmulo de água (Tabela 4). MANDAL et al. (2003), estudando a EUC do sorgo, obtiveram resultados médios que variaram de 8,85 a 15,36 $\mathrm{kg} \mathrm{ha}^{-1} \mathrm{~mm}^{-1}$, com precipitação variando de 247,4 a $351,4 \mathrm{~mm}$. A EUC dos genótipos estudados na pesquisa variou de 94,37 a $126,25 \mathrm{~kg} \mathrm{ha}^{-1} \mathrm{~mm}^{-1}$, resultado bastante superior à média observada por SILVA et al. (2011), de 44,64kg ha-1 $\mathrm{mm}^{-1}$.

Algumas caraterísticas podem explicar a elevada PMS em decorrência da elevada EUC. Segundo SAUCEDO (2008), o sorgo apresenta sistema radicular bastante ramificado, camada de cera que reveste as folhas e caules e maior número de estômatos do que o observado na cultura do milho. Geralmente, entra em períodos de dormência ou repouso vegetativo durante veranicos, e volta a crescer quando há disponibilidade de água.

A EUC das plantas em ambientes semiáridos é uma variável de importância relevante, pois reflete a capacidade da cultura de tolerar as condições de baixa precipitação e distribuição irregular, assim como acúmulo de água (ACA). No entendimento de que a água é um dos nutrientes mais escassos em regiões semiáridas, a técnica de produção de silagem de sorgo torna-se favorável, devido a possibilitar a preservação da água contida no alimento, já que os valores médios variaram $(\mathrm{P}>0,05)$ de 220,60 a 348,41 $\mathrm{kg} \mathrm{ha}^{-1} \mathrm{~mm}^{-1}$ de chuva.

A produção animal em regiões semiáridas é exclusivamente dependente da oferta de forragem durante o período de estiagem, sendo este um dos principais gargalos enfrentados pela cadeia produtiva de grandes e pequenos ruminantes. O sorgo é alternativa viável, devido às características xerófilas apresentadas neste estudo.

\section{CONCLUSÃO}

As cultivares estudadas apresentam elevada eficiência de uso de chuva e produtividade,

Tabela 3 - Valores médios de altura de planta (AP), diâmetro do colmo (DC), número de nós (NN), número de folhas vivas (NFV) e tamanho médio de folhas (TMF).

\begin{tabular}{|c|c|c|c|c|c|}
\hline Cultivar & AP m & $\mathrm{DC} \mathrm{mm}$ & $\mathrm{NN}$ & NFV & TMF cm \\
\hline 'Ponta negra' & $2,74 a$ & 17,75 & $9,50 a$ & $6,50 \mathrm{a}$ & $76,00 \mathrm{a}$ \\
\hline 'SF 15' & $1,86 b$ & 16,50 & $7,37 b$ & $6,51 \mathrm{a}$ & $57,25 a b$ \\
\hline 'IPA 1011' & $1,30 \mathrm{~b}$ & 13,87 & $3,50 c$ & $2,75 b$ & $53,62 b$ \\
\hline 'IPA 2502' & $1,53 b$ & 13,87 & $6,00 \mathrm{~b}$ & $4,25 b$ & $62,25 a b$ \\
\hline 'IPA 46742’ & $1,67 b$ & 17,62 & $7,50 \mathrm{~b}$ & 4,62ab & $66,62 \mathrm{ab}$ \\
\hline CV (\%) & 17,90 & 13,31 & 12,09 & 19,13 & 15,01 \\
\hline
\end{tabular}

Médias seguidas de letras diferentes na coluna diferem entre si pelo teste de Tukey $(\mathrm{P}<0,05)$.

Ciência Rural, v.43, n.10, out, 2013. 
Tabela 4 - Eficiência do uso da chuva (EUC) e acúmulo de água (ACA) de cultivares de sorgo.

\begin{tabular}{lcc}
\hline Cultivar & EUC $\left(\mathrm{kg} \mathrm{ha}^{-1} \mathrm{~mm}^{-1}\right)$ & ACA kg ha-1 $\left.\mathrm{mm}^{-1}\right)$ \\
\hline 'Ponta negra' & 105 & 348,41 \\
'DIPAP SF 15' & 94,23 & 276,31 \\
'IPA 1011' & 126,25 & 252,42 \\
'IPA 2502' & 102,67 & 220,60 \\
'IPA 467' & 97,37 & 262,46 \\
CV (\%) & 22,62 & 348,41 \\
\hline
\end{tabular}

${ }^{1} \mathrm{CV}$ - coeficiente de variação.

demonstrando adaptabilidade às condições edafoclimáticas do semiárido Paraibano. Como não houve diferença no rendimento forrageiro e na eficiência do uso da chuva, as diferentes características agronômicas apresentadas entre os genótipos podem influenciar o valor nutritivo. Assim, recomenda-se a cultivar 'IPA 1011', pela maior participação de panícula.

\section{REFERÊNCIAS}

EDVAN, R.L. et al. Utilização de adubação orgânica em pastagem de capim-buffel (Cenchrus ciliaris cv. 'Molopo'). Archivos de Zootecnia, v.59, n.228, p.499-508, 2010. Disponível em: <http:// www.uco.es/organiza/servicios/publica/az/php/az.php?idioma_gl obal=0\&revista=159\&codigo=1901>. Acesso em: 20 nov. 2011.

FERREIRA, D.F. SISVAR: um programa para análises e ensino de estatística. Revista Simposiun, v.6, p.36-41, 2008. Disponível em: <http://www.fadminas.org.br/symposium/12_edicoes/artigo_5. pdf>. Acesso em: 16 abr. 2011.

LIMA, C.D.S. et al. Adição de uréia e da levedura Saccharomyces cerevisiae no enriquecimento protéico da palma forrageira (Opuntia fícus indica L.) cv. 'miúda'. Revista Magistra, v.16, n.1, p.01-08, 2004.

McDONALD, P. et al. The biochemistry of silage. 2.ed. Marlow: Chalcombe, 1991. 340p. MANDAL, D.K. et al. Water use efficiency of sorghum (Sorghum bicolor) in catenary soils as influenced by varying rainfall. Journal of the Indian Society of Soil Science, v.51, n.3, p.223-228, 2003. Disponível em: <http:// www.indianjournals.com/ijor.aspx?target=ijor:jisss \&volume $=51 \&$ issue $=3 \&$ article $=002>$. Acesso em: 20 nov. 2010.

NEUMANN, M. et al. Avaliação de diferentes híbridos de sorgo (Sorghum bicolor, L. Moench) quanto aos componentes da planta e silagens produzidas. Revista Brasileira de Zootecnia, v.31, n.1, p.302-312, 2002 (supl.). Disponível em: <http://dx.doi. org/10.1590/S1516-35982002000200003>. Acesso em: 16 set. 2011. doi: 10.1590/S1516-35982002000200003.

RAMOS, J.P.F. et al. Crescimento vegetativo de Opuntia ficusindica em diferentes espaçamentos de plantio. Revista Caatinga, v.24, n.3, p.41-48, 2011. Disponível em: <http://periodicos. ufersa.edu.br/revistas/index.php/sistema/article/view/1602/4743>. Acesso em: 12 dez. 2011.

ROCHA JÚNIOR, V.R. et al. Avaliação de sete genótipos de sorgo (Sorghum bicolor (L.) Moench) para produção de silagem: I. Padrão de fermentação. Arquivo Brasileiro de Medicina Veterinária e Zootecnia, v.52, n.5, p.506-511, 2000. Disponível em: <http:// dx.doi.org/10.1590/S0102-09352000000500018>. Acesso em: 26 nov. 2011. doi: 10.1590/S0102-09352000000500018.

RODRIGUES FILHO, O. et al. Produção e composição bromatológica de quatro híbridos de sorgo forrageiro [Sorghum bicolor (L.) Moench] submetidos a três doses de nitrogênio. Ciência Animal Brasileira, v.7, n.1, p.37-48, 2006. Disponível em: <http://www.revistas.ufg.br/index.php/vet/article/view/389/364>. Acesso em: 10 dez. 2011.

SAUCEDO, O.M. Empleo del sorgo en la alimentación animal y humana. In: TALLER NACIONAL SOBRE EMPLEO DEL SORGO. Villa Clara, Cuba: Universidad Central de Las Villas. 2008. p.69-117.

SILVA, T.C. et al. Agronomic divergence of sorghum hybrids for silage yield in the semiarid region of Paraiba. Revista Brasileira de Zootecnia, v.40, n.9, p.1886-1893, 2011. Disponível em: $<$ http://dx.doi.org/10.1590/S1516-35982011000900007>. Acesso em: 05 jan. 2012. doi: 10.1590/S1516-35982011000900007.

TABOSA, J.N. et al. Comportamento de cultivares de sorgo forrageiro em diferentes ambientes agroecológicos dos estados de Pernambuco e Alagoas. Revista Brasileira de Milho e Sorgo, v.1, n.2, p.47-58, 2002. Disponível em: <http://rbms.cnpms.embrapa. br/index.php/ojs/article/view/22>. Acesso em: 15 set. 2012.

ZAGO, C.P. Cultura do sorgo para produção de silagem de alto valor nutritivo. In: SIMPÓSIO SOBRE NUTRIÇÃO DE BOVINOS, 4., 1991, Piracicaba, SP. Anais... Piracicaba: Fundação de Estudos Agrários “Luiz de Queiroz”, 1991. p.169-217.

ZANINE, A.M. et al. Populações microbianas e nutricionais nos órgãos do capim-tanzânia antes e após a ensilagem. Ciências Agrárias, v.28, n.1, p.143-150, 2007. Disponível em: <http://www.uel.br/revistas/uel/index.php/semagrarias/article/ view/2570/2235>. Acesso em: 20 ago. 2011. 